Canadian Journal of Higher Education

Revue canadienne d'enseignement supérieur

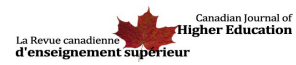

\title{
Building an Inclusive Campus: Developing Students' Intercultural Competencies Through an Interreligious and Intercultural Diversity Program
}

\author{
Amy Rose Green, Adriana Tulissi, Seth Erais, Sharon Lynn Cairns et Debbie \\ Bruckner
}

Volume 48, numéro 3, 2018

URI : https://id.erudit.org/iderudit/1057128ar

DOI : https://doi.org/10.7202/1057128ar

Aller au sommaire du numéro

Éditeur(s)

Canadian Society for the Study of Higher Education

ISSN

2293-6602 (numérique)

Découvrir la revue

\section{Citer cet article}

Green, A., Tulissi, A., Erais, S., Cairns, S. \& Bruckner, D. (2018). Building an Inclusive Campus: Developing Students' Intercultural Competencies Through an Interreligious and Intercultural Diversity Program. Canadian Journal of Higher Education / Revue canadienne d'enseignement supérieur, 48(3), 43-64. https://doi.org/10.7202/1057128ar

\section{Résumé de l'article}

Les institutions post-secondaire affirment le besoin de cultiver la compétence interculturelle (CIC) chez les étudiant(e)s. Par contre, la façon dont ces institutions peuvent effectuer ce projet n'est pas encore exploré en profondeur. L'objectif de l'étude des méthodes variées actuel était l'enquête des changements de CIC (N-35) chez les étudiant(e)s post-secondaires en suivant la participation d'un programme de diversité interreligieuse et interculturelle, basée sur les changements des résultats de l'inventaire interculturel de développement (IID). En employant une analyse thématique qui s'agite d'un questionnaire post-programme, nous avons déterminé une triangulation de l'information disponible et avons fourni plus d'aperçu des changements vécus par les participants. Les résultats quantitatifs révèlent des augmentations significatives chez les étudiant(e)s en général selon leur CIC. Ils démontrent aussi des diminutions significatives de disparité entre la CIC perçue de l'étudiant(e) et leur CIC actuelle. Les résultats qualitatifs révèlent en général cinq thèmes principaux : (1) les perspectives mutables, (2) l'amélioration des compétences de l'engagement interculturel, (3) la connection, (4) l'action inspirante (5) la croissance personnelle. Les implications pour la recherche et la pratique sont abordées dans notre discours.
Copyright (c) Amy Rose Green, Adriana Tulissi, Seth Erais, Sharon Lynn Cairns, Debbie Bruckner, 2018
Ce document est protégé par la loi sur le droit d'auteur. L'utilisation des services d'Érudit (y compris la reproduction) est assujettie à sa politique d'utilisation que vous pouvez consulter en ligne.

https://apropos.erudit.org/fr/usagers/politique-dutilisation/ 
Canadian Journal of Higher Education Revue canadienne d'enseignement supérieur

Volume 48, No. 3, 2018, pages $43-64$

\title{
Building an Inclusive Campus:
}

\section{Developing Students' Intercultural}

\section{Competencies Through an Interreligious and Intercultural Diversity Program}

Amy R. Green, Adriana Tulissi, Seth Erais, Sharon L. Cairns, \& Debbie Bruckner University of Calgary

\begin{abstract}
Post-secondary institutions are increasingly recognizing the need to foster intercultural competence (ICC) in students; however, the ways in which these institutions can do so has not been fully explored. The purpose of the current mixed methods study was to investigate changes in post-secondary students' ICC $(N=35)$ following participation in an interreligious and intercultural diversity program, based upon changes in students' scores on the Intercultural Development Inventory (IDI). A thematic analysis of post-program questionnaires was used to triangulate the data and provide more insight into changes experienced by participants. Quantitative results revealed significant increases in students' overall ICC, and significant decreases in the discrepancy between students' perceived ICC and their actual ICC. Qualitative results revealed five overall themes: (1) shifting perspectives, (2) enhancing intercultural engagement skills, (3) connecting, (4) inspiring action, and (5) personal growth. Implications for research and practice are discussed.
\end{abstract}

\section{Résumé}

Les institutions post-secondaire affirment le besoin de cultiver la compétence interculturelle (CIC) chez les étudiant(e)s. Par contre, la façon dont ces institutions peuvent effectuer ce projet n'est pas encore exploré en profondeur. L'objectif de l'étude des méthodes variées actuel était l'enquête des changements de $\mathrm{CIC}(\mathrm{N}-35)$ chez les étudiant(e)s post-secondaires en suivant 
la participation d'un programme de diversité interreligieuse et interculturelle, basée sur les changements des résultats de l'inventaire interculturel de développement (IID). En employant une analyse thématique qui s'agite d'un questionnaire post-programme, nous avons déterminé une triangulation de l'information disponible et avons fourni plus d'aperçu des changements vécus par les participants. Les résultats quantitatifs révèlent des augmentations significatives chez les étudiant(e)s en général selon leur CIC. Ils démontrent aussi des diminutions significatives de disparité entre la CIC perçue de l'étudiant(e) et leur CIC actuelle. Les résultats qualitatifs révèlent en général cinq thèmes principaux : (1) les perspectives mutables, (2) l'amélioration des compétences de l'engagement interculturel, (3) la connection, (4) l'action inspirante (5) la croissance personnelle. Les implications pour la recherche et la pratique sont abordées dans notre discours.

Intercultural competence (ICC) can be conceptualized as "the capability to shift cultural perspective and appropriately adapt behavior to cultural difference and commonalities" (Hammer, 2015a, p. 26). Post-secondary institutions are increasingly recognizing the need to foster ICC in students, preparing them to function more effectively in a global community (Hammer, 2011). Indeed, students at many colleges and universities across North America come from diverse cultural, linguistic, religious, and national backgrounds; thus, the higher education sector holds great potential in helping cultivate ICC (Bennett, Volet, \& Fozdar, 2013). However, the ways in which educational institutions can reach this potential has yet to be fully realized.

\section{Developing Intercultural Competence Within Post-Secondary Education}

There are several ways in which post-secondary institutions aim to help students develop ICC, from informal to more formal opportunities (Soria \& Troisi, 2014). Several studies have investigated the development of ICC following enrolment in study-abroad programs (e.g., Jones, Hof, \& Tillman, 2016; Stebleton, Soria, \& Cherney, 2013). In general, studies show a positive relationship between participation in study-abroad programs and ICC development (Anderson \& Lawton, 2015). Several authors have reported that study-abroad students showed greater gains in ICC than did control groups of students studying on campus (e.g., Anderson \& Lawton, 2012; Vande Berg, Connor-Linton, \& Paige, 2009).

However, not all study-abroad experiences have a consistent positive impact on students' ICC. For example, Davies, Lewis, Anderson, and Bernstein (2015) explored whether participation in a combination of an on-campus and a short-term study-abroad course would increase ICC in school psychology students compared to those who participated in the on-campus course only. The authors found no measureable growth in ICC in either group. The authors concluded that the short-term nature of the study-abroad program may have contributed to its lack of impact on ICC and suggested that that ICC programs should be ongoing and encourage students' active participation in their own ICC development. It also appears that not all study-abroad experiences are created equal. Stebleton et al. (2013) surveyed nearly 100,000 undergraduate students from 12 large public universities in the United States to investigate the relationship between different types of travel/study-abroad 
experiences and students' development of ICC. The authors found that formal study-abroad programs that were intentionally designed to foster deeper engagement among students were positively associated with ICC development. When compared to travelling abroad for recreational purposes or informal education, formal study-abroad experiences enhanced ICC more significantly in all five ICC areas they investigated (understanding the complexities of global issues, applying disciplinary knowledge in a global context, linguistic and cultural competency, working with people from other cultures, and working comfortably with people from other cultures). The authors hypothesized that these differences were a result of the intentionality and structure of the formal study-abroad programs.

Study-abroad activities may not be accessible or affordable for all students (Soria \& Troisi, 2014). For example, students of colour are less likely to study abroad than white students (Dessoff, 2006). This may be due to various factors; for example, fears of encountering racism abroad, familial obligations, and a lack of faculty members of colour leading the programs (Dessoff, 2006; Van Der Meid, 2003). Moreover, females may be more likely to participate in study-abroad programs than males (Dessoff, 2006; Thirolf, 2014). Thus, in order to offer opportunities for all students, it is important that post-secondary institutions provide on-campus opportunities for ICC development. These types of opportunities have been referred to as "internationalization at home" activities (Osfield, 2008). Soria and Troisi (2014) investigated whether undergraduate students' engagement in internationalization at home activities (on-campus international activities, enrolment in international coursework, interactions with international students, and participation in international co-curricular activities) developed students' ICC similarly to study-abroad opportunities. The authors surveyed 15,807 undergraduate students from nine large public universities in the United States and found that internationalization at home activities yielded greater gains in self-reported ICC competencies than study-abroad activities. Results also demonstrated that students were more likely to participate in internationalization at home efforts than in travel-abroad opportunities, and were more likely to participate in informal activities related to ICC (e.g., interacting with international students) and co-curricular international activities (e.g., attending an international performance) than in more formal opportunities (e.g., enrolling in a course with an international theme). Thus, informal and co-curricular internationalization at home activities appear to be an important components of ICC development for students; however, more research is needed to better understand the ways in which these types of opportunities foster ICC.

\section{Measuring Intercultural Competence: The Developmental Paradigm}

Deardorff (2011) suggested that assessment should be integrated throughout targeted interventions to measure students' ICC development. One such assessment is the Intercultural Development Inventory (IDI; Hammer, 2011), which is based on Bennett's (1986) Developmental Model of Intercultural Sensitivity (DMIS). The DMIS explains people's worldviews and the ways in which they construct cultural difference along a continuum of development (Bennett, 1986). Based on the theoretical framework of the DMIS, Hammer and Bennett (1998) developed the IDI to assess ICC based upon five Developmental Orientations (Hammer, 2011; see Table 1). These orientations reflect the ways in which people shift their cultural perspectives and adapt their behaviours to both cultural differences and commonalities. Results from the IDI are organized along the Intercultural 
Development Continuum (IDC), which is a "Developmental Paradigm" (Hammer, 2015c) that ranges from the monocultural mindsets of Denial and Polarization, through the transitional orientation of Minimization, to the intercultural or global mindsets of Acceptance and Adaptation (Hammer, 2012b). As individuals' perceptions of cultural differences become more complex, their potential to develop ICC increases. The IDI also measures Cultural Disengagement, which is the degree to which an individual or group experiences a sense of alienation from their own cultural community. Although various models and theories of ICC pervade the literature (see Spitzberg and Changnon, 2009, for a more thorough discussion), the Developmental Paradigm (based upon the DMIS) provides the foundation from which we conceptualize and understand ICC in the current study.

Table 1. Summary of IDI developmental continuum orientations: Perceptions and behaviours

Denial

An orientation that may recognize more observable cultural differences (e.g., food) but lack recognition of deeper cultural differences (e.g., conflict resolution styles); may assume commonalities and be disinterested in or avoid cultural differences.

Polarization An orientation that takes an overly critical view of cultural differences; may see differences in terms of "us" and "them." This can take the form of either "defense" or "reversal":

Defense An uncritical view toward one's own cultural values and practices and an overly critical view toward other cultural values and practices; may exhibit a sense of "superiority" toward other cultural practices.

Reversal An overly critical orientation toward one's own cultural values and practices and an uncritical view toward other cultural values and practices.

Minimization An orientation that highlights cultural commonality and universal values and principles that may mask deeper recognition and appreciation of cultural differences.

Acceptance An orientation that recognizes and appreciates patterns of cultural difference and commonality in one's own and other cultures.

Adaptation An orientation that is capable of shifting cultural perspective and changing behaviour in culturally appropriate and authentic ways.

Cultural A sense of disconnection or detachment from a primary cultural group. Disengagement

Adapted from the Intercultural Development Inventory Resource Guide by permission of the author, Mitchell R. Hammer, Ph.D., IDI, LLC. Copyright 1998, 2003, 2007, 2015 Mitchell R. Hammer, IDI, LLC. All Rights Reserved. 


\section{Purpose of the Current Study}

Although previous research has suggested that on-campus and co-curricular activities are important avenues for the development of ICC, more research is needed to tease out the benefits of such activities (Soria \& Troisi, 2014). Although there are many opportunities for exposure to multicultural environments at post-secondary institutions (e.g., language training, cultural events), these opportunities are not necessarily designed with the objective of increasing ICC (Fabregas Janeiro, 2009). Little Canadian-based research has explored whether participation in an intentionally-designed, on-campus, co-curricular program increases ICC (as based on scores on the IDI) in post-secondary students. To address this gap, the purpose of the current research study was to investigate changes in students' ICC, based upon changes in students' scores on the IDI, following participation in an interreligious and intercultural diversity program.

\section{Objectives, Theory, and Mechanisms of the Kaleidoscope Project}

The specific program students were enrolled in for this study was called the Kaleidoscope Project, which is hosted at a large university in Western Canada. Although a more detailed breakdown of the program will be provided in the procedure section of this paper, the theoretical underpinnings and mechanisms of the program are outlined here. The Kaleidoscope Project is currently offered once per year. Through pre-program workshops and a weeklong immersion component, its purpose is to encourage a more pluralistic and inclusive campus community and invite students to engage in learning, conversation, and action with others who may have different backgrounds or viewpoints.

The Kaleidoscope Project is guided by transformational learning theory, which combines positive development with learning (Mezirow, 1991). According to Mezirow (1991), "transformation can lead developmentally toward a more inclusive, differentiated, permeable, and integrated perspective" (p. 155). This theory is in line with Hammer's (2015c) Developmental Paradigm, which describes how people develop along a continuum of increasingly complex ways of constructing cultural difference. According to transformational learning theory, adults learn best when their frames of reference (thoughts, feelings, behaviours, and values) are challenged (Mezirow, 2000). To challenge students' frames of reference and support their ICC development, the Kaleidoscope Project uses specific pedagogical mechanisms (i.e., experiential learning, critical thinking, self-reflection, and cultural mentoring) that can lead to students' transformation.

\section{Experiential Learning}

Deardorff (2011) argued that "intercultural learning is transformational learning, which requires experiences (often beyond the classroom) that lead to this transformation" (p. 70). As such, experiential learning, which emphasizes direct experience and incontext action (Kolb, 2014), is a critical component of the Kaleidoscope Project. Through this framework, participants in the Kaleidoscope Project step into a wide variety of religious worlds around the city. Daily, they encounter new traditions and communities to help them develop understanding of diversity and the complexity of challenges facing religious and non-religious communities. Students are also invited to observe or participate in religious practices at respective sacred spaces, and throughout the program they interact with other students from diverse backgrounds. 


\section{Critical Thinking}

The Kaleidoscope Project utilizes a case method approach (Pierce, 2015) to initiate critical thinking - that is, the ability to reflect and withhold judgment before making a decision (Facione, 2010). Throughout the program, students are provided with case studies that are related to religion in the public sphere and the communities visited. In working through these case studies, participants are encouraged not to focus on finding the "right" answer, but rather to engage critically in the process. As students begin to engage with the case, they explore some of the questions that will arise for them in their professional or public lives. Through discussion, students become active participants who are asked to analyze situations, examine and refine their points of view, listen carefully to other responses, and construct creative responses to conflict (Pierce, 2015). Furthermore, throughout the program students keep a critical incident journal. They are encouraged to interpret and analyze events and how they impact their values and beliefs, and to discuss and think critically about the benefits and challenges of living in a democratic, secular, and pluralistic society.

\section{Self-Reflection}

Hammer (2015a) has argued that intercultural competence development depends on interventions that help students increase both their cultural self-awareness and their cultural other-awareness (e.g., awareness of differences between their own cultural values and those of other cultural groups). The Kaleidoscope Project emphasizes cultural selfand other-reflection and challenges participants to examine what is important to them, to express this respectfully, and to engage with others whose identity and values differ from their own. Not only do students utilize individual journalling and reflection activities before and after the program, there are ongoing intentional reflection opportunities with other students and project leaders.

\section{Cultural Mentoring}

Hammer (2012b) described cultural mentoring as "guided reflection on the students' cultural experience" (p. 130). This mentoring "facilitates students' reflection on their encounters with cultural difference and commonality" (p. 130) and is developmentally grounded in participants' IDI results. In the Kaleidoscope Project, after completing the IDI, participants are provided with an individual profile that outlines their overall placement on the Intercultural Development Continuum. Furthermore, they are given an individualized Intercultural Development Plan with suggestions for how to increase ICC. Prior to starting the program, participants attend one-on-one debriefing sessions with a qualified administrator to go over their results and their individualized Intercultural Development Plan. Throughout the program, interventions are developmentally targeted to participants' IDI results. Furthermore, students work extensively with project leaders on the impacts, experiences, and challenges they encounter.

\section{Method}

The purpose of this study was to describe changes in post-secondary students' ICC, indicated by their scores on the IDI, following their participation in an interreligious and intercultural diversity program at a large urban university. We also aimed to de- 
scribe self-reported changes that participants perceived in ICC following participation in the program. A mixed methods approach was used, integrating qualitative data from post-program questionnaires with the quantitative data from the IDI. The rationale for this approach was that, when used in combination, quantitative and qualitative methods complement each other and can provide a more in-depth picture of the research problem (Johnson \& Turner, 2003). Indeed, Medina-Lopez-Portillo (2004) recommended that research using the IDI should triangulate results with qualitative data to provide a more thorough understanding of students' experiences.

\section{The Intercultural Development Inventory (IDI v3)}

The IDI is a 50-item, electronically administered assessment tool that measures individuals' intercultural competence (ICC), which is defined as "the capability to shift cultural perspective and appropriately adapt behavior to cultural differences and commonalities" (Hammer, 2015a, p. 26). The IDI has been found to possess high cross-cultural validity and reliability. In constructing the instrument, protocols were followed to ensure that it is not culturally biased or susceptible to social desirability effects (Hammer, 2011; Hammer, Bennett, \& Wiseman, 2003). As previously noted, the IDI is theoretically grounded in the Developmental Model of Intercultural Sensitivity (DMIS; Bennett, 1986). This model is comprised of an intercultural developmental continuum of five increasingly more nuanced and knowledgeable orientations toward cultural competency/sensitivity (Denial, Polarization, Minimization, Acceptance, and Adaptation; Hammer, 2011; see Table 1).

IDI results include a "Developmental Orientation" (DO; that is, where participants actually fall on the continuum) and a "Perceived Orientation" (PO; that is, where participants believe they fall on the continuum). An "Orientation Gap" (OG) score comprises the difference between these two scores. A gap score of seven points or more is indicative that one has overestimated one's intercultural competence. Some profiles reveal a Trailing Orientation (TO), which indicates that, when individuals are placed in an "intercultural stress point," they revert back to an earlier spot on the continuum. The IDI also measures Cultural Disengagement (CD), which is considered a separate dimension of assessment and is the degree to which individuals experience a sense of disconnectedness or alienation from their own cultural community (Hammer, 2011). Scores of less than 4.00 on this scale indicate that individuals are not "resolved" and may be experiencing a lack of involvement in core aspects of their culture.

Once the IDI is completed, an individual profile is created that outlines the respondent's overall placement on the Intercultural Development Continuum (IDC). Furthermore, an individualized Intercultural Development Plan is created with suggestions for how to increase ICC. The IDI can only be administered by a qualified administrator who receives training in the IDI assessment tool. When results of the assessment are shared with participants, a qualified administrator who implemented the IDI assessment is required to offer a one-on-one debrief with the participant on the profile report and development plan.

\section{Post-Program Questionnaire}

The post-program questionnaire was developed specifically for the Kaleidoscope Project. It consists of open-ended questions designed to elicit information about students' per- 
ceptions about how their ICC (including values, beliefs, knowledge, and skills) changed as a result of participating in the program. Furthermore, it explores students' understanding of the overall impact of the program on them, and how they might apply their learning in their everyday lives.

\section{Research Questions and Hypotheses}

The main research question was as follows:

1. Does intercultural competence change (as measured by changes in DO scores on the IDI) for students after participating in an interreligious and intercultural diversity program?

In addition to changes in DO scores on the IDI, findings from the post-program questionnaire added qualitative understanding about the ways in which students perceived changes in ICC following participation in the interreligious and intercultural diversity program. An additional research question for the study was:

2. Is there a change in the discrepancy between perceived intercultural competence and actual intercultural competence (as measured by changes in OG scores on the IDI) for students after participating in an interreligious and intercultural diversity program? That is, is there a change in how well students perceive their own intercultural competence after participating in the program?

We hypothesized that, following participation in the Kaleidoscope Project, there would be an increase in students' ICC (i.e., an increase in DO scores on the IDI) and a decrease in the discrepancy between students' perceived and actual ICC (i.e., a decrease in OG scores on the IDI). We hypothesized that these changes would be associated with the specific transformational learning mechanisms employed to increase students' ICC (i.e., experiential learning, critical thinking, self-reflection, and cultural mentoring).

\section{Research Design}

The study used a mixed methods approach using a convenience sample. For quantitative data, a pre-test/post-test design was used. Paired-samples $t$-tests identified changes in mean IDI scores (DO and OG) from Time 1 to Time 2 for the group of students. Qualitative data from the post-program questionnaire were analyzed using thematic analysis (Braun and Clarke, 2006).

\section{Participants}

The 35 participants who completed the Kaleidoscope Project over a two-year period were invited to participate in the study. Participation in the research project was not mandatory to participate in the Kaleidoscope Project; however, all 35 participants agreed to partake. Recruitment for the Kaleidoscope Project took place through various outreach activities on campus. Potential participants applied for the program, and invitations for group interviews were offered to all who completed applications. For those interviewed, contractual offers to participate in the program were given along with a schedule for payment, as there was also a cost associated with taking part in program. 
To take part in the program, participants had to be registered as students and agree to attend all four scheduled pre-program workshops before attending the weeklong immersion portion of the program. Thirty-one participants were undergraduate students, two were graduate students, and two were mature students. Participants were enrolled in various academic departments, including business, nursing, social work, engineering, religious studies, kinesiology, and astrophysics. Participants identified with a range of religious and cultural identities.

\section{Procedure}

Institutional ethics approval was obtained to conduct this research. The Kaleidoscope Project occurred over the course of four months, and included four pre-program workshops and a weeklong immersion component that took place during the university's winter reading break. The program started with the first pre-program workshop, which was an opportunity for participants to meet one another and get an in-depth introduction to the program. The remainder of the first pre-program workshop was spent creating respect guidelines that would help the students during discussion and engagement with the group, as well as with communities and individuals that would be encountered throughout the program. Also during the first pre-program workshop, participants were introduced to the research study and signed a consent form to participate.

Directly following the first pre-program workshop, all participants were emailed a link and unique username and password to complete the online IDI and were asked to complete this in the next seven days. Participants were also asked to sign up online for a time to meet with an IDI-trained qualified administrator (the second author) for a 30-minute, one-on-one meeting to debrief their individualized IDI profile and development plan. They were emailed a copy of these two documents prior to this meeting so that they could preview their results. During the one-on-one meeting, the administrator explained the results of each participant's IDI and development plan, and answered any questions. The administrator also emphasized the importance of creating two or three goals related to their IDI development plan and the Kaleidoscope Project (e.g., spending one hour a week working on their development plan).

The remaining three pre-program workshops explored major project themes (e.g., intercultural competence, interreligious engagement, pluralism, and religious diversity). For those students who were unable to make one or more of the pre-program workshops (including partial absences), additional opportunities were given for condensed activities and topics during two separate time periods to ensure all received the same curriculum. At the end of each pre-program workshop, students were asked to complete reflection questions on their experience and learning.

During the weeklong immersion part of the program, participants visited over 10 sacred spaces and cultural restaurants in Calgary. Each day, students were given a case study to work through that was related to religion in the public sphere and the communities visited. Each day ended with a debrief that included three parts: an interreligious and intercultural journal that engaged the students in critical self-reflection, time spent with another student one-on-one to allow for discussion, and small group reflection circles focusing on a word that was significant to that day's encounters. Every evening, students and leaders gathered to express gratitude for the day. On the last day of the weeklong immersion part of the program, all students completed the post-program questionnaire. 
After completion of the program, participants were emailed a link and unique username and password to complete their second online IDI and asked to complete this in the next seven days. Upon completion, they were emailed a copy of their individualized IDI profile and intercultural development plan. They were invited to initiate a meeting with the qualified IDI administrator to debrief their results; this was not mandatory and only two students chose to do so.

\section{Data Collection and Analysis}

Data were collected across the four months of the Kaleidoscope Project in 2015/2016 and 2016/2017.

Quantitative data. Once the IDIs were completed by all participants, the IDI software generated individual profiles that illustrated participants' numerical scores, which were plotted along the Intercultural Development Continuum. Participants' pre- and postscores were first analyzed using the IDI software analysis program. IDI data were then exported into the Statistical Package for the Social Sciences (SPSS) for further analysis.

Qualitative data. The six phases of thematic analysis proposed by Braun and Clarke (2006) were used to conduct an inductive analysis on transcripts of written post-program questionnaire answers. First, two of the authors read and reread the transcripts to familiarize themselves with the content. Second, these same authors separately identified initial codes by identifying relevant features of the data. Third, the researchers met and discussed their preliminary codes and collated interpretations into further themes. Fourth, coded data were developed into a thematic map, whereby the researchers considered the alignment of themes and created preliminary definitions for each. Following this analysis, an audit was carried out whereby two facilitators of the Kaleidoscope Project were provided with the raw transcripts, the thematic map, and the preliminary definitions, to check that the interpretations made were warranted based on the data. Minor changes to terminology were made based on these facilitators' recommendations. Fifth, the researchers returned to the entire dataset and considered the validity of each theme. It was determined that the thematic map worked in relation to the dataset, and then, sixth, the important aspects of each theme were organized into written accounts.

\section{Results}

\section{Quantitative Data}

Intercultural competence (ICC) was measured using the IDI before and after completion of the Kaleidoscope Project. Paired samples $t$-tests were used to analyze the data and determine if there were significant changes between students' scores (DO and OG) from Time 1 to Time 2 (see Table 2). Frequencies for participants' subscale scores for Time 1 and Time 2 are presented in Table 3.

Results indicated a significant increase in the mean Developmental Orientation (DO) score, $t(34)=-2.95, p<.01$. This suggests that there was a significant increase in students' intercultural competence from Time 1 to Time 2. More specifically, DO scores at Time $1(M=94.43, \mathrm{SD}=13.10)$ increased on average by $8.01 \%$ at Time $2(M=102.03, \mathrm{SD}=$ 17.22). Cohen's $d(d=.50)$ indicated a moderate effect size. As the frequencies in Table 3 show, there were more students in Denial, Polarization, and Minimization at Time 1 than 
at Time 2, and more students in Acceptance and Adaptation at Time 2 than at Time 1. DO scores for Time 1 ranged from 59.50 to 118.57, while DO scores for Time 2 ranged from 71.03 to 135.27 .

Table 2. t-Tests and Cohen's d for Developmental Orientation and Orientation Gap Scores for Time 1 and Time $2(N=35)$

\begin{tabular}{|c|c|c|c|c|c|c|c|c|}
\hline & \multicolumn{7}{|c|}{ Mean } & \multirow{2}{*}{$\begin{array}{l}\text { Effect size } \\
\text { (Cohen's } d)\end{array}$} \\
\hline & Time 1 & SD 1 & Time 2 & SD 2 & $\begin{array}{l}\text { Change } \\
\text { score }\end{array}$ & $\begin{array}{c}t- \\
\text { value }\end{array}$ & $\underset{\text { (2-tailed) }}{\text { Sig. }}$ & \\
\hline $\begin{array}{l}\text { Developmental } \\
\text { Orientation } \\
\text { (DO) }\end{array}$ & 94.43 & 13.10 & 102.03 & 17.22 & -7.60 & -2.95 & $.006^{* *}$ & .50 \\
\hline $\begin{array}{l}\text { Orientation } \\
\text { Gap (OG) }\end{array}$ & 27.41 & 8.68 & 23.37 & 10.59 & 4.04 & 2.41 & $.022^{*}$ & .42 \\
\hline
\end{tabular}

Table 3. Frequencies of participants' subscale scores $(N=35)$

\begin{tabular}{lrrcrrr}
\hline & \multicolumn{3}{c}{ Time 1 } & \multicolumn{3}{c}{ Time 2 } \\
\cline { 2 - 7 } & Frequency & Percent & $\begin{array}{c}\text { Cumulative } \\
\text { Percent }\end{array}$ & Frequency & Percent & $\begin{array}{c}\text { Cumulative } \\
\text { Percent }\end{array}$ \\
\hline Denial & 1 & 1.4 & 2.9 & 0 & 0.0 & 0.0 \\
Polarization & 8 & 11.4 & 25.7 & 7 & 10.0 & 20.0 \\
Minimization & 24 & 34.3 & 94.3 & 19 & 27.1 & 74.3 \\
Acceptance & 2 & 2.9 & 100.0 & 7 & 10.0 & 94.3 \\
Adaptation & 0 & 0.0 & 100.0 & 2 & 2.9 & 100.0 \\
\hline
\end{tabular}

Results also indicated a significant decrease in the mean Orientation Gap (OG) score, $t(34)=2.41, p<.05$. This suggests that there was a significant decrease in the discrepancy between students' perceived ICC and actual ICC from Time 1 to Time 2. More specifically, OG scores at Time $1(M=27.41, \mathrm{SD}=8.68)$ decreased on average by $14.74 \%$ at Time $2(M$ $=23.37, \mathrm{SD}=10.59)$. Cohen's $d(d=.42)$ indicated a moderate effect size. At both Time 1 and Time 2, the mean Perceived Orientation (PO) score fell within the Acceptance range, indicating an overestimation of ICC by participants at both time points; however, the discrepancy between DO and PO scores did, as previously noted, significantly decrease (see Figure 1). 


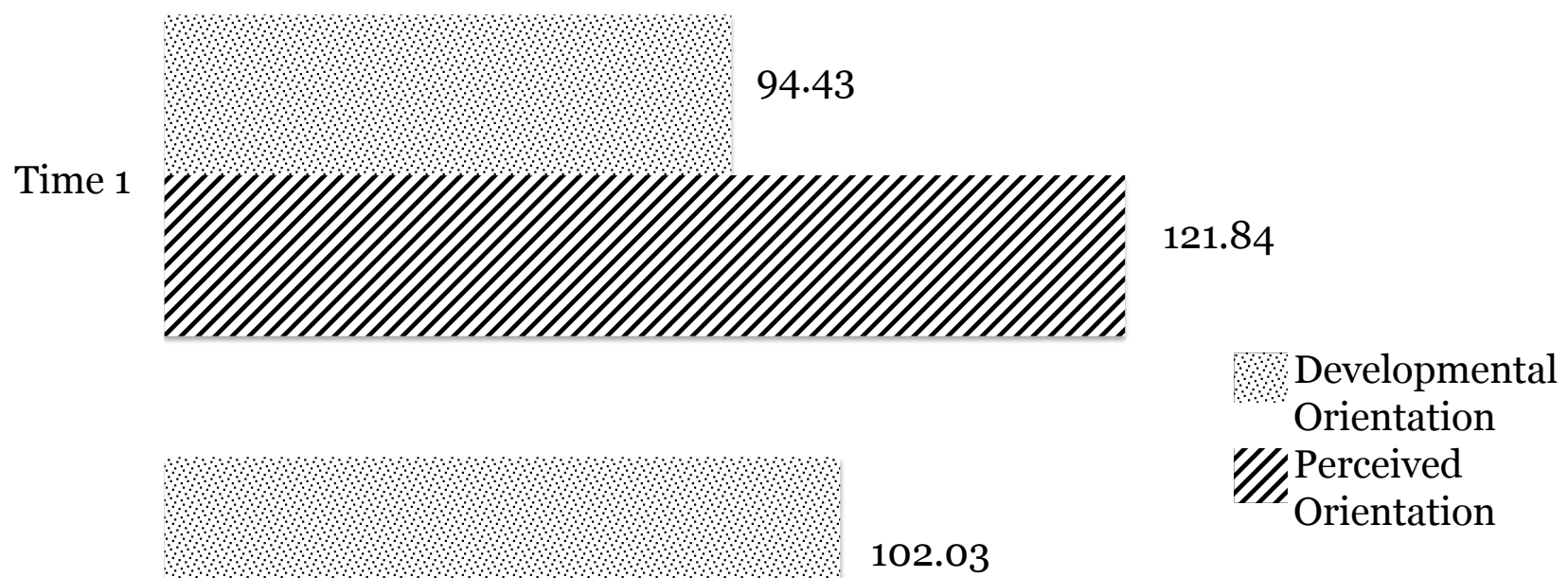

Time 2

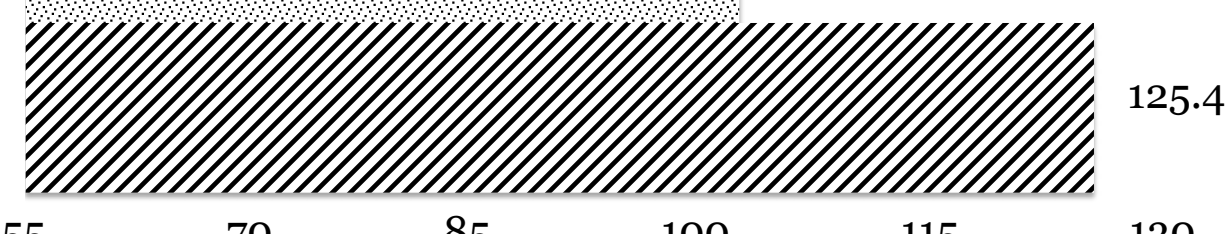

$\begin{array}{lllllll}55 & 70 & 85 & 100 & 115 & 130 & 145\end{array}$

Figure 1. Mean Developmental Orientation and Perceived Orientation scores at Time 1 and Time 2.

\section{Qualitative Data}

Qualitative results from the post-program questionnaires were used to understand self-reported changes in ICC that participants experienced as a result of participating in the Kaleidoscope Project. Results are presented under five central themes (shifting perspectives, enhancing intercultural engagement skills, connecting, inspiring action, and personal growth).

1. Shifting perspectives. The theme shifting perspectives encompassed the idea that participants' knowledge and beliefs about diverse cultures and religions shifted following their participation in the Kaleidoscope Project. All participants expressed an increased understanding about the intricacies of various cultures, religions, and belief systems. Several participants also noted that they learned not to stereotype or make assumptions about individuals who identify with a particular cultural group; as one participant expressed, "I've also learnt not to put people into boxes as everyone might practice their religion [differently] or believe in different things." Similarly, another participant noted that, "everyone practices their religion in their own way -7 billion people $=7$ billion religions." Many participants discussed an enhanced valuing of diversity and different points of view-even when these perspectives differed from their own. Said one participant: "I learned not to minimize the differences but rather acknowledge and appreciate it." Participants also discussed enhanced open-mindedness; for example, one participant 
noted, "I learnt not to judge people because of prior perceptions, but work toward understanding others and respecting their viewpoints, beliefs, and values."

2. Enhancing intercultural engagement skills. Participants expressed various ways in which participation in the Kaleidoscope Project contributed to their intercultural engagement skills. This involved an enhanced perceived ability to respond to religious and cultural dilemmas, and an improved perceived ability to competently and respectfully engage with individuals who identified as being part of diverse cultures and religions. Participants noted that engaging with different case studies and with other students/community members helped them feel more comfortable and respectful in sometimes challenging situations/conversations. For example, one participant said, "I hope I learned how to authentically speak my truth while opening the space for dialogue and conversation about all cultures." Another expressed that they learned "how to critically think and analyze situations and conflicting ideas." Similarly, participants noted that visiting different sacred spaces in the community taught them "how to engage in interfaith dialogue" and "comfortably engage with members of a religious community."

3. Connecting. Participants discussed the ways in which they connected with others and built a sense of community-both with fellow participants and members of the larger community. With other students, participants described making "amazing connections" wherein they experienced "fun and laughter" and many "intentional" and "engaging" conversations. For some participants, this sense of connection was surprising. Said one participant: "I didn't think that the program would foster the sense of community that it did." Within this sense of connection and community was an appreciation for both the similarities and differences amongst individuals, and how they were able to find "common ground" among individuals from various backgrounds and who adhered to diverse belief systems. One participant said that "it [the program] opened my eyes to other faiths and how they are connected." Another participant summed up this experience by noting "how truly connected everyone is and that we all just use different paths to get to the light." Some participants expressed that the experiential aspects of the program connected them to human experience in a way they would not have been able to in a classroom or through a book.

4. Inspiring action. The theme of inspiring action involved participants' desire and felt sense of competency to continue with multicultural engagement after completion of the program. Participants expressed their commitment to continue using the skills they learned in the program. They shared that different values and perspectives would endure in their everyday lives; for instance "the need to question, learn, and understand." There was a sense of commitment toward social justice efforts; for example, one participant expressed "the urgency I feel to make a difference. I've been pretty apathetic, but what I learned and the community that was created over the course of the program has made me feel empowered and determined to make a difference." Many participants expressed their belief that there should be more opportunities for students to participate in the Kaleidoscope Project (or programs like it); one participant said, "I wish it could be a prerequisite for graduation."

5. Personal growth. Participants expressed vast personal growth from their participation in the Kaleidoscope Project. One participant shared that he "broke out of [his] shell;" another wrote that "there was a radical and wonderful change from me being unsure, nervous, and prejudiced toward the 'other' to me being curious, more confident, and understanding of other people." Participants discussed how they learned about the im- 
portance of self-reflection and how this contributed to enhanced self-awareness. Engagement in self-reflection was viewed as important to continue with after completion of the program. Many participants also shared that the experience in the program pushed them outside their comfort zones as they were placed in difficult or sometimes uncomfortable situations. One participant said, "I was challenged intellectually and emotionally," while another said that "the most valuable skill I learned...was to embrace being uncomfortable and to ask when I am uncertain.” To sum up their experience, another participant said, "Words cannot describe how life-changing this program is."

\section{Discussion}

This study sought to describe changes in intercultural competence (ICC), as indicated by changes in Developmental Orientation (DO) scores on the IDI, among post-secondary students before and after completion of the Kaleidoscope Project, an intercultural and interreligious diversity program. Results suggest that participation in the Kaleidoscope Project was positively associated with improvements in students' ICC. More specifically, there was a significant increase in students' DO scores after completing the Kaleidoscope Project. Secondly, this study aimed to describe any changes in the discrepancy between perceived and actual ICC for students by examining whether their Orientation Gap (OG) scores decreased. Results indicated that OG scores significantly decreased from Time 1 to Time 2, suggesting that participation in the Kaleidoscope Project was associated with students' abilities to more realistically evaluate their own level of ICC. Qualitative results from post-program questionnaires provide further insight into the specific changes in ICC students experienced as a result of participating in the Kaleidoscope Project. More specifically, participants described how the program helped them to (1) shift perspectives, (2) enhance intercultural engagement skills, (3) connect with others, (4) inspire action, and (5) encourage personal growth.

We hypothesized that changes in participants' ICC (based upon changes in IDI scores) would be associated with the specific transformational learning mechanisms employed by the program (i.e., experiential learning, critical thinking, self-reflection, and cultural mentoring). Although participants were not asked specifically in the post-program questionnaire about which aspects of the program encouraged changes in ICC, qualitative results offer insight into the ways these learning mechanisms may have contributed to changes in students' ICC. Each will be described in more detail below.

\section{Experiential Learning}

Experiential learning is a critical component of the Kaleidoscope Project, as participants are immersed in the community to learn in situ about different cultures and religions. In the post-program questionnaire, participants wrote about how visiting and participating in different cultural spaces was beneficial in helping them shift their perspectives (Theme 1) and enhancing their intercultural engagement skills (Theme 2). Hammer's (2015a) argument that his Developmental Paradigm is "grounded in the dynamic interaction that arises between individuals" (p.13) has particular relevance for the findings of the current study. Indeed, ample opportunities for interactions amongst group members, facilitators, and community members may have also been associated with the 
changes in participants' IDI scores. As Eck (2006) cautioned, "mere diversity without real encounter and relationship will yield increasing tensions in our societies" (p. 1); thus, the Kaleidoscope Project offered several opportunities for meaningful engagement and relationship-building for participants (both amongst themselves and with members of the community). In the post-program questionnaires, participants wrote about how these meaningful interactions with others added a sense of community to the learning experience (Theme 3). Furthermore, participants wrote about how finding themselves in new (and sometimes uncomfortable) environments and situations promoted personal growth by encouraging them to challenge themselves (Theme 5).

\section{Critical Thinking}

Bennett (2013) noted that the development of ICC "parallels the development of critical thinking" (p. 109). Research by Miller and Tucker (2015) supports this claim. These authors found there was a significant relationship between critical thinking skills and ICC amongst 2,241 mid-career Air Force officers. Similarly, in the current study, it appears that critical thinking was an important part of ICC development and was associated with changes in participants' IDI scores. Indeed, in post-program questionnaires, participants wrote about how engaging with different case studies positively influenced their intercultural engagement skills (Theme 2), by shifting the ways in which they would approach issues related to religion and culture.

\section{Self-Reflection}

Jackson (2008) suggested that promoting self-awareness can help people become more cognizant of their ICC limitations. Thus, the Kaleidoscope Project's emphasis on self-reflection activities may have helped participants improve their self-awareness and contributed to the significant decreases in students' OG scores. Indeed, in the post-program questionnaires, participants discussed the importance of self-reflection for their learning, and how participation in the program contributed to personal growth by enhancing their self-awareness (Theme 5).

Soria and Troisi (2014) suggested that more research is needed to explore whether students' self-reported ICC reflects their actual ICC. Indeed, the results of the present study suggest that self-perception is not, in fact, always an adequate measure of cultural competency. An OG score that is higher than seven points is considered an overestimation of one's level of intercultural competence; at both Time 1 and Time 2, 100\% of participants overestimated their IDI developmental scores. In fact, a mean OG score of 27.41 at Time 1 and 23.37 at Time 2 indicates that students quite significantly overestimated their levels of ICC. Thus, although students' self-perception of their ICC improved following participation in the Kaleidoscope Project, ongoing self-reflection and examination seems to be an important component of enduring ICC development. This is an important area for future study.

\section{Cultural Mentoring}

Past research has indicated that cultural mentoring plays a critical role in increasing students' ICC, as measured by the IDI (Engle \& Engle, 2004). In the current study, an 
important component of cultural mentoring was that all participants received individual feedback about their IDI profiles. In 2015, Davies et al. used the IDI to explore whether participation in a study-abroad course impacted ICC in school psychology students compared to those who took the same course at home. These authors found no measureable growth in ICC in either group. They noted that few participants in their study opted to receive individual feedback on their IDI profiles, which, they concluded, "may have impacted the self-reflection/self-awareness process that is essential to intercultural development" (p. 387). Thus, it is possible that the guided reflection that occurred within the individual feedback sessions provided in the current study contributed to changes in participants' IDI scores. Furthermore, it is possible that the action planning that occurred during the guided reflection sessions was helpful in inspiring participants to make changes (Theme 4) in their everyday lives.

Lokkesmoe, Kuchinke, and Ardichvili (2016) argued that ICC training "should be customized to be developmentally appropriate" (p. 167). Furthermore, Hammer (2015b) argued that:

Training and education efforts that are targeted developmentally for the primary orientation of the individual can lead to gains in intercultural competence (that is, higher posttest scores); however, interventions that are not developmentally targeted based on IDI results would not necessarily be expected to increase an individual's intercultural competence (no significant differences in pre/posttests). (p. 12)

Thus, in the Kaleidoscope Project, cultural mentoring was tailored to meet individual students' needs. This potentially played an important role in changes in participants' IDI scores. For example, the ways in which transformational learning was encouraged among the participants differed slightly depending on the students' developmental orientation at Time 1. For instance, the majority of students were within Minimization at Time 1, which is a developmental orientation that is in transition between a monocultural and intercultural mindset. Those in Minimization often focus on cultural commonalities and universal values and principles that may also mask deeper recognition and appreciation of cultural differences (Hammer, 2012a). Thus, key development goals for those in Minimization involved mentoring students to help them work on intentional self-understanding and intentional other-understanding, and seeing similarities while also working to understand deeper cultural differences. During the program, many participants in Minimization looked for similarities among the different religious traditions, including looking for similarities within their own religious tradition (if applicable). This is a common place to be on the continuum for those exploring different religious and cultural traditions. By incorporating critical incident journalling (done alone by the students), pairing them up with another student to discuss, and then working in small groups to reflect on the day, students had several intentional opportunities to reflect on both commonalities and differences. Additionally, students were encouraged to think about the impact of these experiences on their own values, beliefs, and identity. 


\section{Limitations and Implications for Research and Practice}

We cannot be certain that the changes in participants' ICC was the result of participating in the Kaleidoscope Project alone and not due to some other factor(s). This is an inherent limitation of the one-group pre-test/post-test design. Certainly, no intervention occurs in isolation, and additional experiences that occurred concurrently with the Kaleidoscope Project may have contributed to changes in participants' ICC. Future research would be well-served to include a control group, in order to increase confidence in the claims made about the impact of participating in an intercultural and interreligious diversity program. However, triangulating quantitative findings with qualitative results from post-program questionnaires provided insight into the specific changes that occurred. Furthermore, although participants were not asked explicitly about which pedagogical mechanisms contributed to these changes, their answers provided suggestions about the learning experiences that facilitated ICC development. In future research, we intend to employ a critical incident study using qualitative interviews to explore the specific aspects of the program that participants viewed as helping and hindering their ICC development.

The small sample size of the study, in addition to the fact that all participants volunteered to take part in the Kaleidoscope Project, means we cannot generalize findings to students across university settings. Furthermore, ICC development is an ongoing and lifelong process; thus, it would be interesting to determine whether DO scores change over time for participants, for example, at a six-month or one-year follow-up. Longerterm follow-up could be built into the design in future replication studies. Additionally, because data were collected over two years of the program, this may limit some of the conclusions drawn. Although the program was delivered with the same overall structure, there were some minor modifications made from Year 1 to Year 2. For example, some of the speakers involved in the program differed due to lack of availability or the intention to expand the breadth of perspectives. Furthermore, there were slight curriculum changes in two of the four pre-program workshops. Additionally, based on a higher occurrence of participants landing in Polarization and a larger number of students in Minimization who had trailing orientations in Denial in Year 2, it was decided that certain content needed to be communicated differently and some readings in the course pack altered. This decision was made intentionally, as past experience informed us that the original readings had the potential to lead to further polarization for students who were not developmentally ready, which could have been detrimental to their learning. Thus, adapting the curriculum each year to meet the students' needs may be an important part of the program; however, further research on this variable is needed. Overall, major learning outcomes and topics did not change from Year 1 to Year 2; thus, the small changes made to the program likely did not have a significant impact on study results.

Finally, another limitation of the study was the cost associated with participation in the program (CAD\$725 per student in Year 1 and CAD\$750 per student in Year 2). Because accessibility of this program was critical, three opportunities for funding were available to apply for. However, we recognize that these funding opportunities did not offset the costs completely, and, as such, financial constraints may have been a barrier for some students. Furthermore, we acknowledge that the development of programs such as the Kaleidoscope Project can be lengthy and costly for institutions; indeed, the current project took 
over one year of research, development, and consultation before a pilot of the program was developed. As such, in institutions where funding and resources are a constraint, similar programs may be more difficult to implement. It is also reasonable to assume that gaining support from institutions that prioritize ICC would be comparatively easier than from institutions that do not. Some institutions may be reluctant to invest in programs that could potentially put them and their students in a vulnerable place if there are issues of safety and/or entrenched religious or cultural marginalization. However, such situations are potentially where ICC programs are needed most. Thus, program developers can ask themselves where religious and ideological diversity is present on campus and consider those in the community who have expertise in diversity education. We suggest that it is critical to utilize these resources in program development and delivery, and to align the goals of the program with the goals of the local setting/institution where possible.

\section{Conclusion}

It is incumbent upon post-secondary institutions to offer intentional, well-designed, and accessible "internationalization at home" programs for students, to help them enrich and develop their ICC. The present study begins to shine light on the benefits of such a program. More specifically, results suggest that an intentionally-designed program that incorporates a broad array of pedagogical mechanisms can positively influence students' ICC. Given the increasingly diverse make-up of North American post-secondary institutions, more research in this area is needed to better understand how programs can enhance students' ICC, in turn fostering more inclusive campuses and communities.

\section{Acknowledgement}

This project was supported in part by an Advanced Education Grant from the Province of Alberta.

\section{References}

Anderson, P. H., \& Lawton, L. (2012). Intercultural development: Study abroad vs. on-campus study. Frontiers: The Interdisciplinary Journal of Study Abroad, 21, 86108. Retrieved from https://frontiersjournal.org/past-volumes/vol-xxi/

Anderson, P. H., \& Lawton, L. (2015). Student motivation to study abroad and their intercultural development. Frontiers: The Interdisciplinary Journal of Study Abroad, 26, 39-52. Retrieved from https://ir.stthomas.edu/cgi/viewcontent.cgi?article=1022\&c ontext=ocbmgmtpub

Bennett, M. (1986). A developmental approach to training for intercultural sensitivity. International Journal of Intercultural Relations, 10(2), 179-195. doi: 10.1016/01471767(86)90005-2

Bennett, M. J. (2013). Intercultural practices: International/multicultural education. In M. J. Bennett (Ed.), Basic concepts of intercultural communication: Paradigms, principles, and practices (2nd ed., pp. 105-136). Boston, MA: Intercultural Press.

Bennett, R. J., Volet, S. E., \& Fozdar, F. E. (2013). "I'd say it's kind of unique in a way": The development of an intercultural student relationship. Journal of Studies in International Education, 17(5), 533-553. doi: 10.1177/1028315312474937 
Braun, V., \& Clarke, V. (2006). Using thematic analysis in psychology. Qualitative Research in Psychology, 3(2), 77-101. doi:10.1191/1478088706qpo63oa

Davies, S. C., Lewis, A. A., Anderson, A. E., \& Bernstein, E. R. (2015). The development of intercultural competency in school psychology graduate students. School Psychology International, 36(4), 375-392.

Deardorff, D. K. (2011). Assessing intercultural competence. New Directions for Institutional Research, 149, 65-79. doi:10.1002/ir.381

Dessoff, A. (2006). Who's not going abroad? International Educator, 15(2), 2027. Retrieved from https://www.nafsa.org/uploadedFiles/NAFSA_Home/Resource_ Library_Assets/Publications_Library/who_s_not_going_abroad.pdf?n=1479

Eck, D. (2006). Resources: What is pluralism? Retrieved from http://pluralism.org/ what-is-pluralism/

Engle, L., \& Engle, J. (2004). Assessing language acquisition and intercultural sensitivity development in relation to study abroad program design. Frontiers: The Interdisciplinary Journal of Study Abroad, 10, 219-236. https://frontiersjournal.org/ past-volumes/vol-x/

Fabregas Janeiro, M. G. (2009). Assessing changes in intercultural sensitivity in students exposed to intercultural experiences supported by the College of Agricultural Sciences and Natural Resources at Oklahoma State University using the Intercultural Development Inventory. Retrieved from ProQuest Dissertations Publishing (3449107).

Facione, P. A. (2010). Critical thinking: What it is and why it counts. Millbrae, CA: Peter A. Facione, Measure Reasons, and the California Academic Press.

Hammer, M. R. (2011). Additional cross-cultural validity testing of the Intercultural Development Inventory. International Journal of Intercultural Relations, 35(4), 474487 .

Hammer, M. R. (2012a). Intercultural Development Inventory v.3 (IDI): Sample individual profile report. Berlin, MD: IDI, LLC. Retrieved from https://idiinventory. com/wp-content/themes/evolution/pdfs/Jose_-_Exemplar_-_Profile_-_August_2012. pdf

Hammer, M. (2012b). The Intercultural Development Inventory: A new frontier in assessment and development of intercultural competence. In M. Vande Berg, R. M. Paige, \& K. H. Lou (Eds.), Student learning abroad (pp. 115-136). Sterling, VA: Stylus Publishing.

Hammer, M. R. (2015a). A resource guide for effectively using the Intercultural Development Inventory (IDI). Berlin, MD: IDI, LLC. Retrieved from http://idiinventory. com/wp-content/uploads/2014/o8/Intercultural\%2oDevelopment\%2oInventory\%20 Resource\%20Guide1.pdf

Hammer, M. R. (2015b). Clarifying inaccurate statements characterizing the Intercultural Development Inventory in Matsumoto and Hwang (2013). JCCP article, retrieved from https://idiinventory.com/wp-content/uploads/2014/o2/ClarifyingInaccurate-Statements-Characterizing-the-Intercultural-Development-08-20-2015.pdf. 
Hammer, M. R. (2015c). The developmental paradigm for intercultural competence research. International Journal of Intercultural Relations, 48, 12-13. doi: 10.1016/j. ijintrel.2015.03.004

Hammer, M. R., \& Bennett, M. J. (1998). The Intercultural Development Inventory. Portland, OR: The IDI Corporation.

Hammer, M. R., Bennett, M. J., \& Wiseman, R. (2003). Measuring intercultural sensitivity: The Intercultural Development Inventory. International Journal of Intercultural Relations, 27(4), 421-443. doi: 10.1016/So147-1767(03)ooo32-4

Jackson, J. (2008). Globalization, internationalization, and short-term stays abroad. International Journal of Intercultural Relations, 32(4), 349-358. doi: 10.1016/j. ijintrel.2008.04.004

Johnson, R. B., \& Turner, L. S. (2003). Data collection strategies in mixed methods research. In A. Tashakkori \& C. Teddlie (Eds.), Handbook of mixed methods in social and behavioral research (pp. 297-319). Thousand Oaks, CA: Sage.

Jones, S. W., Hof, D. D., \& Tillman, D. R. (2016). Assessing global service-learning: A mixed-methods approach to evaluating students' intercultural development. International Journal of Psychology: A Biopsychosocial Approach, 18, 29-50. doi: 10.7220/2345024X.18.2

Kolb, D. (2014). Experiential learning: Experience as the source of learning and development (2nd ed.). Upper Saddle River, NJ: Pearson Education.

Lokkesmoe, K. J., Kuchinke, P., \& Ardichvili, A. (2016). Developing cross-cultural awareness through foreign immersion programs: Implications of university study abroad research for global competency development. European Journal of Training and Development, 4O(3), 155-170. doi: 10.1108/EJTD-07-2014-0048

Medina-Lopez-Portillo, A. (2004). Intercultural learning assessment: The link between program duration and the development of intercultural sensitivity. Frontiers: The Interdisciplinary Journal of Study Abroad, 10, 179-199. https://frontiersjournal. org/past-volumes/vol-x/

Mezirow, J. (1991). Transformative dimensions of adult learning. San Francisco, CA: Jossey-Bass.

Mezirow, J. (2000). Learning to think like an adult: Core concepts of transformation theory. In J. Mezirow \& Associates (Eds.), Learning as transformation: Critical perspectives on a theory in progress (pp. 3-33). San Francisco, CA: Jossey-Bass.

Miller, J. W., \& Tucker, J. S. (2015). Addressing and assessing critical thinking in intercultural contexts: Investigating the distance learning outcomes of military leaders. International Journal of Intercultural Relations, 48, 120-136. doi: 10.1016/j. ijintrel.2015.07.002

Osfield, K. J. (2008). Internationalization of student affairs and services: An emerging global perspective. Washington, DC: NASPA.

Pierce, E. (2015). "What is at stake?" Exploring the problems of pluralism through the case method. Interreligious Studies, 17. http://irstudies.org/journal/what-is-at-stakeexploring-the-problems-of-pluralism-through-the-case-method-by-ellie-pierce/ 
Soria, K. M., \& Troisi, J. (2014). Internationalization at home alternatives to study abroad: Implications for students' development of global, international, and intercultural competencies. Journal of Studies in International Education, 18(3), 261-280. doi: 10.1177/1028315313496572

Spitzberg, B. H., \& Changnon, G. (2009). Conceptualizing intercultural competence. In D. K. Deardorff (Ed.), The Sage handbook of intercultural communication (pp. 2-52). Thousand Oaks, CA: Sage.

Stebleton, M. J., Soria, K. M., \& Cherney, B. T. (2013). The high impact of education abroad: College students' engagement in international experiences and the development of intercultural competencies. Frontiers: The Interdisciplinary Journal of Study Abroad, 22, 1-24. https://frontiersjournal.org/past-volumes/volume-xxii/

Thirolf, K. Q. (2014). Male college student perceptions of intercultural and study abroad programs. Journal of Student Affairs Research and Practice, 51(3), 246-258. doi: 10.1515/jsarp-2014-0026

Van Der Meid, J. S. (2003). Asian Americans: Factors influencing the decision to study abroad. Frontiers: The Interdisciplinary Journal of Study Abroad, 9, 71-110. https:// frontiersjournal.org/past-volumes/vol-ix/

Vande Berg, M., Connor-Linton, J., \& Paige, R. M. (2009). The Georgetown Consortium Project: Interventions for students living abroad. Frontiers: The Interdisciplinary Journal of Study Abroad, 18, 1-75. https://frontiersjournal.org/past-volumes/vol-xviii/

\section{Contact Information}

Amy R. Green

Educational Studies in Counselling Psychology

Werklund School of Education

University of Calgary

amy.green@ucalgary.ca

Amy R. Green is a PhD candidate in Counselling Psychology in the Werklund School of Education at the University of Calgary. Her dissertation research explores the experience of embodiment among newcomer women in Canada; her other research interests include women's health and wellbeing, expressive arts therapies, and arts-based research methods. Amy received an MA in Counselling Psychology from the University of British Columbia and a BA in Psychology from the University of Victoria.

Adriana Tulissi is the Manager of the Faith \& Spirituality Centre at the University of Calgary where she supports students, staff, and faculty on building a more inclusive campus focusing on education and awareness on interreligious and intercultural programming and religious accommodation, among many other things. Adriana is currently working on her LLB. at the University of London, England. She has also completed her MA in History of Christianity at Iliff School of Theology in Denver, CO, having also graduated from the University of Calgary with a BA in Religious Studies and a BA in Communications and a minor in Management. 
Seth Erais is the Engagement Coordinator for the Faith \& Spirituality Centre at the University of Calgary and an advocate for LGBTQA inclusion in religious settings. His work in creating the Kaleidoscope Project helps to support student development of intercultural competencies and promotes a more inclusive and pluralistic campus community through programming and activism. Throughout his degree in Religious Studies at the University of Calgary, his interests have ranged from South Asian religions, interreligious dialogue, religious literacy, and pedagogy in religious studies education in postsecondary settings.

Sharon L. Cairns is Associate Professor of Counselling Psychology in the Werklund School of Education. Her research interests include program evaluation and post-secondary counselling.

Debbie Bruckner is currently serving as the Senior Director of Student Wellness, Access \& Support at the University of Calgary, where she has worked since 2006. During this time, she developed an integrated wellness service for students. She was active in developing and now implementing the Campus Mental Health Strategy. Previous to that Debbie has been a sessional instructor at Mount Royal University, the University of Calgary, and Athabasca University. Debbie worked for 17 years at Bow Valley College, including the roles of Registrar and Manager of Counselling and Manager of Human Resources. Previous to entry into post-secondary employment, Debbie was Executive Director of the Calgary Sexual Assault Centre for 10 years. Her particular interests include leadership, mentoring, team work, inter-professional collaboration, and wellness. 